Self-esteem and Body Mass Index from Adolescence to

Mid-adulthood. A 26-year Follow-up

Kiviruusu, Olli

2016-06

Kiviruusu, O , Konttinen , H , Huurre , T , Aro , H, Marttunen , M \& Haukkala , A 2016 , '

Self-esteem and Body Mass Index from Adolescence to Mid-adulthood. A 26-year Follow-up

' , International Journal of Behavioral Medicine , vol. 23 , no. 3 , pp. 355-363 . https://doi.org/10.1007/s12529-015-95

http://hdl.handle.net/10138/224017

https://doi.org/10.1007/s12529-015-9529-4

publishedVersion

Downloaded from Helda, University of Helsinki institutional repository.

This is an electronic reprint of the original article.

This reprint may differ from the original in pagination and typographic detail.

Please cite the original version. 


\title{
Self-esteem and Body Mass Index from Adolescence to Mid-adulthood. A 26-year Follow-up
}

\author{
Olli Kiviruusu $^{1}$ - Hanna Konttinen ${ }^{2}$. Taina Huurre ${ }^{1,3}$. \\ Hillevi Aro $^{1,4}$ - Mauri Marttunen ${ }^{1,5}$ - Ari Haukkala ${ }^{2}$
}

Published online: 21 December 2015

(C) International Society of Behavioral Medicine 2015

\begin{abstract}
Purpose This study examined the developmental trajectories of self-esteem and body mass index (BMI) from adolescence to mid-adulthood and the way the association between selfesteem and BMI changed during a 26-year follow-up. Methods Participants of a Finnish cohort study in 1983 at 16 years $(N=2194)$ were followed up at ages $22(N=1656)$, $32(N=1471)$, and $42(N=1334)$ using postal questionnaires. Measures at each time point covered self-esteem and selfreported weight and height. Analyses were done using latent growth curve models (LGM) and difference scores.

Results In LGM analyses among females both the initial levels $(r=-0.13)$ and slopes $(r=-0.26)$ of the self-esteem and BMI trajectories correlated negatively. Among males, there were no significant correlations between self-esteem and BMI growth factors. The association between increasing BMI and decreasing self-esteem among females was strongest between ages 22 and $32(r=-0.16)$, while among males, increases in BMI and self-esteem correlated positively $(r=0.11)$ during that period. Among females, cross-sectional correlations between self-
\end{abstract}

Olli Kiviruusu

olli.kiviruusu@thl.fi

1 Department of Health, National Institute for Health and Welfare, P.O. Box 30, 00271 Helsinki, Finland

2 Department of Social Research, University of Helsinki, Helsinki, Finland

3 Department of Health and Social Welfare, City of Vantaa, Vantaa, Finland

4 School of Health Sciences, University of Tampere, Tampere, Finland

5 University of Helsinki and Helsinki University Hospital, Adolescent Psychiatry, Helsinki, Finland esteem and BMI showed an increasing trend $(p<0.001)$ from age $16(r=-0.07)$ to age $42(r=-0.17)$, whereas among males negative correlation $(r=-0.08)$ emerged only in mid-adulthood at age 42.

Conclusion Among females, higher and increasing BMI is associated with lower and more slowly increasing selfesteem. This association is not restricted to adolescent years but persists and gets stronger in mid-adulthood. Among males, associations are weaker but indicate more age-related differences. The results highlight the need for interventions that tackle weight-related stigma and discrimination, especially among women with higher body weight and size.

Keywords Self-esteem · Body mass index · Weight status · Developmental trajectory $\cdot$ Prospective cohort study

\section{Introduction}

Self-esteem, as the evaluative component of the self-concept, is vitally important for good mental health [1], and research indicates that it predicts a variety of other important life outcomes $[2,3]$. For those being overweight or obese, maintaining a positive self-image might prove a challenge, since the Western culture so strongly markets the thin body ideal as its prevailing norm, especially for females [4, 5]. Moreover, low self-esteem may hinder successful weight loss and maintenance in the current obesogenic environment, and failures in weight control may further reduce self-esteem [6], leading to a vicious cycle between diminishing self-esteem and higher body weight. In their meta-analysis, Miller and Downey [7] reported self-esteem and measures of heavyweight to be inversely related at small to moderate levels. However, 
the association between self-esteem and overweight/ obesity has typically been studied in samples of children and adolescents [8], while longitudinal studies are scarce and prospective studies extending beyond adolescent years even more so.

Although the prevalences of overweight and obesity in western countries are high [9]; the cultural norms of ideal body shape prefer thinner looks, while overweight and obesity are generally stigmatized [10]. As the self-concept is in part a reflection of how we think others view us [11], the negative attitudes and prejudice (whether anticipated or actually experienced) towards the overweight/obese are likely to affect the self-concept of those belonging to that group, leading to a lowered self-esteem and psychological ill health $[8,12]$. The association between self-esteem and obesity is likely to be bidirectional, however. Indeed, some prospective studies have indicated that low self-esteem in baseline is associated with increased body mass index (BMI) or waist-to-hip ratio after several years of follow-up even when controlling for baseline weight levels $[3,13]$.

Previous research shows that the association between selfesteem and overweight/obesity is more pronounced among females [7]. Most likely, this is because the standards for thinness and pressures towards the thin body shape ideal are far more stringent for females than males [4]. Consequently, body dissatisfaction is common among females, and it begins at an early age [14]. Among males, associations between body size and self-esteem are weaker, perhaps in part because the tissue type (fat vs. muscle) is also of importance, not merely the weight [15]. Another potentially important moderator of the self-esteem-heavyweight association is age. Miller and Downey [7] argued that the relation could be weaker in adulthood, but stronger in adolescence and early adulthood, since appearance issues relating to dating and mating are more important at this time. This contention was also partly supported in their meta-analysis, in that the inverse relation between selfesteem and heavyweight was stronger during college years than later in adulthood [7].

However, no previous study has investigated how the relationship between self-esteem and overweight/obesity develops during the maturational processes from adolescence to adulthood and whether this development is different between genders. In this prospective study with a 26year-long follow-up and a sample which at baseline comprised practically a full age cohort of one Finnish city, the present research examines the association between selfesteem and BMI and its development from age 16 to mid-adulthood at age 42 years. The study question is addressed at the level of individual growth trajectories and change scores, as well as by comparing the cross-sectional correlations at different ages, i.e., how age moderates the association between self-esteem and BMI. The moderating role of gender is also studied at all levels of analyses.

\section{Subjects and Methods}

\section{Subjects}

The original target population included all Finnishspeaking ninth-grade pupils attending secondary school in the spring of 1983 in Tampere, an industrial university city in southern Finland with 166000 inhabitants at that time. In 1983, 2194 pupils ( $96.7 \%$ of the target population; 1071 females, 1123 males; mean age 15.9 (SD 0.3) years; all Caucasian), completed a questionnaire during school hours. Participants in the 1983 baseline study were followed up by postal questionnaires in $1989(N=1656$, $75.5 \%), 1999(N=1471,67.0 \%)$, and $2009(N=1334$, $60.8 \%$ ) when the subjects were 22,32 , and 42 years of age, respectively.

Of the participants, $87.6 \%(N=1922)$ participated in at least one follow-up panel after the baseline, $70.1 \%$ $(N=1538)$ in at least two, and $45.6 \%(N=1001)$ in all three follow-up panels. Attrition was examined by correlating study variables at age 16 with the number of waves of participation (range 1-4). On average, there were 3.0 responses per participant, the number being higher in females than males $(3.3$ vs. $2.8, p<0.001)$. However, response was not related to self-esteem or BMI at age 16 either among females or males.

\section{Measures}

\section{Self-esteem}

The measure of self-esteem [16] consisted of seven statements of self-worth resembling those used in Rosenberg's measure [17]. The statements were "I believe in myself and in my possibilities," "I wish I was different from how I am" (reversed), "I suffer from feelings of inferiority" (reversed), "I think I have many good qualities," "I feel I lack selfconfidence" (reversed), "I am capable of doing the same as others," and "I am often dissatisfied with myself" (reversed). The self-esteem score was calculated as the mean of item scores (theoretical range 1-5). Cronbach's alphas ranged from 0.80 to 0.89 in the different panels.

\section{Body Mass Index}

BMI was calculated by dividing self-reported weight $(\mathrm{kg})$ by the square of self-reported height (m). No systematic information was available on pregnancies, but for those females who spontaneously reported being pregnant at the time of completing the questionnaire $(N=36)$, BMI was coded as missing in that panel. 


\section{Statistical Analyses}

Analyses were done using Mplus 5.2 software (Muthén \& Muthén, Los Angeles, CA, USA) [18] and PASW Statistics 18.0 (SPSS Inc., Chicago, IL, USA). The trajectories of selfesteem and BMI were analyzed with latent growth models (LGM) within the structural equation modeling (SEM) framework. In a linear LGM time loadings of the slope factor are fixed to represent linearly growing time, in this case $0,0.6$, 1.6, and 2.6 (in tens of years) for the consecutive study panels. Non-linear trajectories can be modeled using higher order growth factors or by estimating some loadings of the slope factor freely from the data [19].

The estimation of the self-esteem growth trajectory has been presented earlier [20]. In brief, the best model fit was achieved with a non-linear model where the last time loading of the slope factor (1.7 in females, 1.5 in males) was estimated freely (for model fit, see Table 2). Also for BMI, linear models were fitted first, then those with a quadratic growth factor, and alternatively, also models where one or two of the time loadings of the slope factor were estimated freely. None of these models as such provided an acceptable fit to the data. Finally, models with both a quadratic factor (with variance constrained to zero to allow estimation) and freely estimated time loadings for the last panel (2.1 in females, 1.7 in males) gave a good representation as to the form of the trajectory, so these models were retained for further analyses (for model fit, see Table 2).

Correlations between the self-esteem and BMI growth factors were obtained from a parallel process LGM where the two growth trajectories were estimated simultaneously in one model. In order to find out whether the association between the change trajectories was different in different developmental periods, the trajectories were "decomposed" into three phases using simple difference scores between consecutive panels. The difference scores were formed by subtracting the value of self-esteem (or BMI) in one panel (e.g., 16 years) from its value in the next panel (22 years); thus, the difference scores represented change from 16 to 22 , from 22 to 32 , and from 32 to 42 years. A model using these difference scores was then specified to examine correlations between the change scores. Finally, to analyze how the association between self-esteem and BMI develops from adolescence to mid-adulthood (i.e., moderation by age), cross-sectional correlations between them were obtained from a saturated model of full correlation matrices between the study variables. All SEM analyses were done first without any adjustments and then with adjusting for basic education at age 22 (completed high school, yes/no): as the results were practically identical, the original estimates without adjustments are presented.

Gender differences in estimates were tested with the $\chi^{2}$ change statistic derived from multigroup analyses, comparing models with and without the parameter of interest constrained to be the same between genders. Similarly, to test whether correlations between self-esteem and BMI were different between study panels, the $\chi^{2}$ change statistic was used to compare models with and without constraining these correlations to be the same across the panels. To deal with missing values due to attrition, the full information maximum likelihood (FIML) estimation method was used, which produces less biased and more reliable results compared with conventional methods of dealing with missing data [21, 22]. Model fit was assessed by the Tucker-Lewis index (TLI), the comparative fit index (CFI), and the root mean square error of approximation (RMSEA). TLI and CFI values $\geq 0.95$ and RMSEA values $\leq 0.06$ were considered to indicate a good fit to the data [23]. As the distributions of self-esteem and BMI deviated slightly from normal, analyses were additionally run with the MLR estimator, which produces standard errors that are robust to non-normality [18]. These sensitivity analyses produced essentially the same results as those presented using the maximum likelihood (ML) estimator.

\section{Results}

Descriptive statistics of the study variables are given in Table 1. Observed means of self-esteem increased from age 16 to 32 years but remained the same between ages 32 and 42, whereas the BMI means grew throughout the study period, as did the prevalences of overweight. In all panels, males had higher self-esteem and BMI than females $(p<0.001)$.

Parameter estimates of the self-esteem and BMI latent growth curves are given in Table 2. Linear slopes of both self-esteem and BMI were positive and significantly different from zero, indicating that self-esteem and BMI increased during the study period. The overall growth patterns of selfesteem and BMI as estimated by the LGM analyses are presented in Fig. 1.

Among females, there was a significant negative correlation $(-0.13)$ between the initial level growth factors of selfesteem and BMI (Table 3). Also, the growth rates of the trajectories were significantly negatively correlated $(-0.26)$ in females, indicating that during the period from age 16 to 42 , an increase in BMI was associated with a slower development in self-esteem. Among males, there were no such associations between the growth factors, and the gender differences regarding these associations were significant (Table 3). There were no correlations between the intercept of the one and the slope of the other trajectory among either females or males.

In order to ascertain that the correlations between the growth factors were not biased due to the non-linearity components of the specified trajectories, a model with only linear slopes (fixed time values representing linear time) for both self-esteem and BMI trajectories was estimated. Although this model gave less than optimal fit to the data $\left(\chi^{2}=643.6\right.$ $[d f=44], p<0.001, \mathrm{CFI}=0.88, \mathrm{TLI}=0.85$, 
Table 1 Descriptive statistics of the study variables by gender

\begin{tabular}{|c|c|c|c|c|c|}
\hline \multirow[b]{2}{*}{ Variable } & \multicolumn{2}{|c|}{ Females $(N=1071)$} & \multicolumn{2}{|c|}{ Males $(N=1123)$} & \multirow{2}{*}{$\begin{array}{l}\text { Gender } \\
\text { difference } \\
p^{*}\end{array}$} \\
\hline & $N$ & Mean $(\mathrm{SD}) / \%(N)$ & $\mathrm{N}$ & Mean $(\mathrm{SD}) / \%(N)$ & \\
\hline Self-esteem $^{\mathrm{a}}$ at age 16 & 1067 & $3.5(0.67)$ & 1105 & $3.8(0.64)$ & $<0.001$ \\
\hline Self-esteem ${ }^{\mathrm{a}}$ at age 22 & 886 & $3.6(0.71)$ & 764 & $3.9(0.67)$ & $<0.001$ \\
\hline Self-esteem $^{\mathrm{a}}$ at age 32 & 803 & $3.9(0.74)$ & 663 & $4.1(0.71)$ & $<0.001$ \\
\hline Self-esteem ${ }^{a}$ at age 42 & 733 & $3.9(0.75)$ & 597 & $4.1(0.67)$ & $<0.001$ \\
\hline $\mathrm{BMI}^{\mathrm{b}}$ at age 16 & 1002 & $19.8(2.20)$ & 1049 & $20.3(2.23)$ & $<0.001$ \\
\hline $\mathrm{BMI}^{\mathrm{b}}$ at age 22 & 874 & $21.6(3.03)$ & 759 & $23.0(2.64)$ & $<0.001$ \\
\hline $\mathrm{BMI}^{\mathrm{b}}$ at age 32 & 758 & $23.8(4.31)$ & 662 & $25.3(3.61)$ & $<0.001$ \\
\hline $\mathrm{BMI}^{\mathrm{b}}$ at age 42 & 716 & $25.5(5.03)$ & 596 & $26.8(4.39)$ & $<0.001$ \\
\hline Overweight $^{\mathrm{c}}$ at age 16 & 1002 & $3.1(31)$ & 1049 & $6.6(69)$ & $<0.001$ \\
\hline Overweight $^{\mathrm{d}}$ at age 22 & 874 & $11.8(103)$ & 759 & 19.4 (147) & $<0.001$ \\
\hline Overweight $^{\mathrm{d}}$ at age 32 & 758 & $28.2(214)$ & 662 & $47.1(312)$ & $<0.001$ \\
\hline Overweight $^{\mathrm{d}}$ at age 42 & 716 & $45.4(325)$ & 596 & $63.4(378)$ & $<0.001$ \\
\hline
\end{tabular}

${ }^{*} p$ values for self-esteem and BMI from $t$ test, for overweight from $\chi^{2}$ test

${ }^{a}$ Range 1-5

${ }^{\mathrm{b}}$ Body mass index, weight $(\mathrm{kg}) /$ height squared $\left(\mathrm{m}^{2}\right)$

${ }^{\mathrm{c}} \mathrm{BMI} \geq 24.37$ (females), BMI $\geq 23.90$ (males), see Cole et al. [39]

${ }^{\mathrm{d}} \mathrm{BMI} \geq 25$
RMSEA $=0.111$ ), it however produced practically the same correlations between the growth factors as the specified nonlinear model selected for the analyses.

The developmental trajectories of self-esteem and BMI were then "decomposed" into three separate phases using simple difference scores between the consecutive study panels. Correlations between these change scores are presented in Table 4. The results show that the changes in self-esteem and BMI were not related in the period from adolescence to young adulthood among either females or males. Correlations between the changes became significant and were most prominent between ages 22 and 32. However, while in females, an increase in BMI during this period meant a decrease (or a slower increase) in self-esteem, among males, an increase in BMI was associated with an increase also in self-esteem. Among females the inverse relation between the changes continued to be prevalent also in the period from age 32 to 42 years, although to a lesser degree.

The development of the association between self-esteem and BMI from adolescence to mid-adulthood as represented by the cross-sectional correlations in the study panels is depicted in Fig. 2. In females, the negative correlations between self-esteem and BMI were significant and increasing in magnitude throughout the study period. This trend of ever stronger correlations was significant as compared to a model where all four correlations were constrained to be equal $\left(\Delta \chi^{2}=17.72, d f=3, p<0.001\right)$. Among males, the correlations between self-esteem and BMI were close to zero, slightly on the positive side if anything, and non-significant between ages 16 and 32. However, there was a clear change in this in the last panel at age 42, when the negative correlation between self-esteem and BMI emerged for the first time among males: the correlations of the first three panels were not significantly different from each other $\left(\Delta \chi^{2}=1.70, d f=2, p=0.427\right)$, but the one in the last panel differed significantly from the other three $\left(\Delta \chi^{2}=9.80, d f=1, p=0.002\right)$.

\section{Discussion}

In the present study, the association between self-esteem and BMI and its development from adolescence to adulthood was explored. Among females, a small, but persistent association, between low self-esteem and high BMI was found, and it became progressively stronger from adolescence to mid-adulthood. This development was evident also at the level of individual growth trajectories of self-esteem and BMI during the study period. Among males, self-esteem and BMI were mainly unrelated, with the correlations found to be weak, and in some instances, to be in the opposite direction than those among females. Also, the pattern of age differences was different as compared to females: the positive association between increasing BMI and increasing self-esteem in young adult males changed to a negative correlation between selfesteem and BMI by mid-adulthood.

When the developmental trajectories of self-esteem and BMI were specified in a single parallel process growth model, the results among females showed significant negative correlations between both the levels and the slopes of the growth trajectories. This means that the self-esteem trajectory follows, 
Table 2 Parameter estimates of the latent growth curve models of self-esteem and BMI, separate models for females and males

\begin{tabular}{|c|c|c|c|c|}
\hline & \multicolumn{2}{|c|}{ Females $(N=1059-1068)$} & \multicolumn{2}{|c|}{ Males $(N=1102-1117)$} \\
\hline & Estimate & $p$ & Estimate & $p$ \\
\hline \multicolumn{5}{|l|}{ Self-esteem ${ }^{a}$} \\
\hline \multicolumn{5}{|l|}{ Means } \\
\hline Intercept & 3.45 & $<0.001$ & 3.82 & $<0.001$ \\
\hline Slope, linear ${ }^{\mathrm{c}}$ & 0.25 & $<0.001$ & 0.19 & $<0.001$ \\
\hline \multicolumn{5}{|l|}{ Variances } \\
\hline Intercept & 0.26 & $<0.001$ & 0.19 & $<0.001$ \\
\hline Slope, linear ${ }^{\mathrm{c}}$ & 0.10 & $<0.001$ & 0.11 & $<0.001$ \\
\hline \multicolumn{5}{|l|}{ Correlation } \\
\hline Intercept with slope & -0.34 & $<0.001$ & -0.24 & 0.005 \\
\hline \multicolumn{5}{|l|}{$\mathrm{BMI}^{\mathrm{b}}$} \\
\hline \multicolumn{5}{|l|}{ Means } \\
\hline Intercept & 19.89 & $<0.001$ & 20.33 & $<0.001$ \\
\hline Slope, linear ${ }^{\mathrm{c}}$ & 3.14 & $<0.001$ & 5.34 & $<0.001$ \\
\hline Slope, quadratic ${ }^{c}$ & -0.51 & $<0.001$ & -1.42 & $<0.001$ \\
\hline \multicolumn{5}{|l|}{ Variances } \\
\hline Intercept & 4.52 & $<0.001$ & 3.85 & $<0.001$ \\
\hline Slope, linear ${ }^{\mathrm{c}}$ & 3.29 & $<0.001$ & 3.02 & $<0.001$ \\
\hline Slope, quadratic ${ }^{\mathrm{c}}$ & 0.00 & N/A & 0.00 & N/A \\
\hline \multicolumn{5}{|l|}{ Correlation } \\
\hline Intercept with linear slope ${ }^{\mathrm{d}}$ & 0.22 & $<0.001$ & 0.14 & 0.015 \\
\hline
\end{tabular}

${ }^{\text {a }}$ Model fit: females $\chi^{2}=13.0(d f=4), p=0.011, \mathrm{CFI}=0.99, \mathrm{TLI}=0.98, \mathrm{RMSEA}=0.046$; males $\chi^{2}=19.7$ $(d f=4), p=0.001, \mathrm{CFI}=0.97, \mathrm{TLI}=0.96, \mathrm{RMSEA}=0.059$

${ }^{\mathrm{b}}$ Model fit: females $\chi^{2}=8.7(d f=2), p=0.013, \mathrm{CFI}=1.00, \mathrm{TLI}=0.99$, RMSEA $=0.056$; males $\chi^{2}=1.9$ $(d f=2), p=0.391, \mathrm{CFI}=1.00, \mathrm{TLI}=1.00 \mathrm{RMSEA}=0.000$

${ }^{\mathrm{c}}$ Linear/quadratic between 16 to 32 years, last time loading estimated freely from the data

${ }^{\mathrm{d}}$ Due to zero variance, correlations with the quadratic slope cannot be computed

Note: parameter estimates of the self-esteem growth curve have been presented earlier in Kiviruusu et al. [20], and they are represented here only for the sake of clarity on average, a lower path among those in the more obese end of the BMI continuum, but also, and more importantly, that it develops less favorably for those females whose BMI increases more rapidly. Considering the 26-year-long study period comprising developmentally quite different phases from adolescence to mid-adulthood, this finding cannot be regarded as a trivial one: the result shows that this is a phenomenon of persistence, manifesting itself at the level of individual developmental paths, not just as mean or group level associations. Comparable studies using individual growth trajectories are hard to find from previous literature. In their study, Mustillo et al. [24] reported self-esteem trajectories in different BMI trajectory groups among girls between ages 9 to 17 years. Their results seem to suggest (direct comparisons between the BMI trajectory groups were not made) that those girls who became obese during adolescence had the poorest, while those formerly obese girls who became non-obese had the most favorable self-esteem development. Although studies analyzing individual level changes are scarce, the long-term and persistent nature of the association between self-esteem and BMI among females has been indicated in other types of longitudinal studies as well. For example, Ternouth et al. [13] reported self-esteem at age 10 to predict weight gain by the age of 30 especially in females.

The persistence of the inverse association between selfesteem and BMI among females was further clarified when the cross-sectional correlations between them in the study panels were analyzed. The results showed a statistically significant trend of progressively stronger correlations between low self-esteem and high BMI from adolescence to mid-adulthood. This was contrary to the idea that issues relating to physical appearance, like overweight and obesity, would lose their meaning as determinants of self-worth as the participants reach mid-adulthood, a type of trend that was indicated by some earlier research findings [7, 25, 26]. Rather, the results seem to suggest that pressures to adhere to cultural beauty ideals do not lose their grip on females as they reach midadulthood. In this sense, our findings resemble more the 
(a) Self-esteem

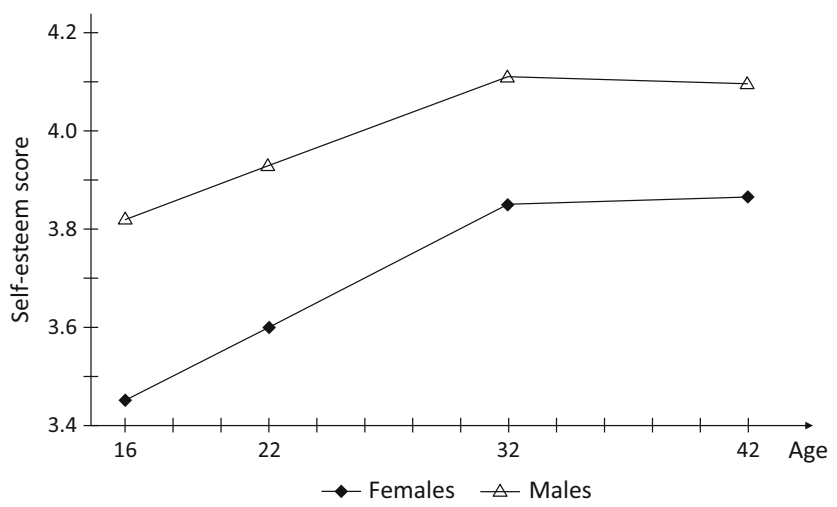

(b) BMI

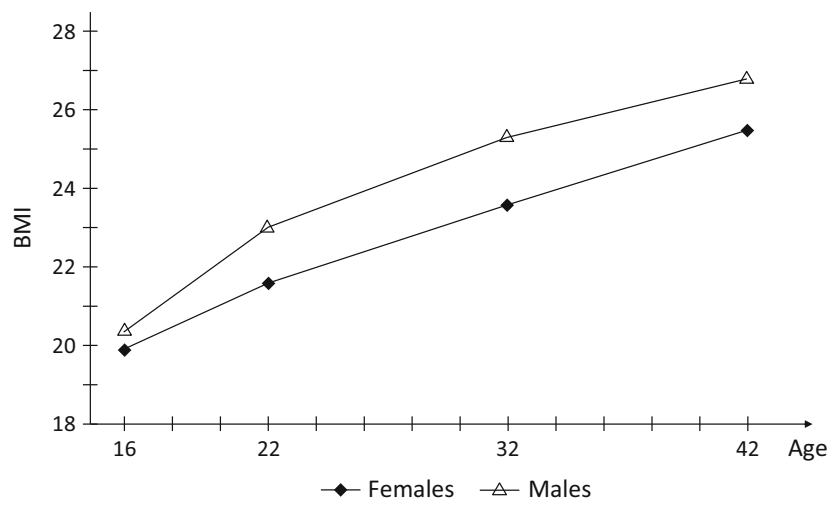

Fig. 1 Estimated self-esteem (a) and BMI (b) trajectories from nonlinear latent growth curve models from age 16 to 42 . Note: the selfesteem growth trajectory (part a) has been presented earlier in Kiviruusu et al. [20]

results reported by Tiggemann and Stevens [27], which showed the correlation between weight concern and low self-esteem to be non-significant below age 30 (and above 50) years, but significant in the age group of 30-49 years, and within this group, being even strongest between the ages of 40 and 49 years. Similarly, in the study by Runfola et al. [28], women in the age group of 35-44 years had the highest degree of body dissatisfaction of all age groups, while also having the highest mean BMI level. Thus, our results might simply reflect the fact that as women age and gain weight, they move further away from the culturally desired body ideal.
It needs to be noticed, however, that the associations between age and body image are complex, and the strength, direction, and linearity of the association depend on the studied aspect of body image [29].

In addition to aging, some cohort-specific effects might be operating here and in part explain the increasing negative correlations between BMI and self-esteem among females. During the study period, from the beginning of 1980 s, our environment has become more and more obesogenic, resulting in the current obesity epidemic [30]. While the thin body ideal for females has prevailed (if not gotten stronger), the gap between the actual mean body shape and size in the population and the prevailing thin ideal has become wider [5]. The obesity epidemic has also made obesity and the related health risks and the costs they are likely to induce for the health care system a constant topic in the public eye. Thus, obesity is now visible not only in contention with the thin beauty ideal, but also with health norms, which currently (quite unduly) emphasize the self-control (or the lack of if) on the part of the obese [31].

Yet another viewpoint to the studied phenomena was achieved by "decomposing" the growth trajectories down into panel to panel changes using difference scores. Although the method employing simple differences is a rather crude one and the results need to be viewed only as suggestive, at face value, these analyses added some new insights to our findings. The most interesting of these-in fact, one of the strongest effects of the study - was the gender divergence that emerged between ages 22 and 32: whereas in females, an increase in BMI during this period was related to a slower development of self-esteem, just the opposite was true for males, among whom gaining weight was associated with gaining self-esteem. While the result among females is understandable given their higher pressures to conform to the thin body ideal, the male side of this finding requires a bit more explanation. The positive association between weight gain and increasing self-esteem is in line with earlier studies reporting young adult males' desire to be heavier [32] and to have more muscles [33]. Research also indicates that males are more likely not to perceive themselves as
Table 3 Correlations between the latent growth factors of self-esteem and BMI trajectories, results from a parallel process multigroup (females, males) model

\begin{tabular}{|c|c|c|c|c|c|}
\hline \multirow[t]{2}{*}{ Correlation } & \multicolumn{2}{|c|}{ Females $(N=1071)$} & \multicolumn{2}{|c|}{ Males $(N=1122)$} & \multirow{2}{*}{$\begin{array}{l}\text { Gender difference } \\
\Delta \chi^{2}, p(d f=1)\end{array}$} \\
\hline & Estimate & $p$ & Estimate & $p$ & \\
\hline Self-esteem intercept with BMI intercept & -0.13 & 0.003 & 0.02 & 0.753 & $5.80, p=0.016$ \\
\hline Self-esteem intercept with BMI slope & 0.01 & 0.843 & -0.09 & 0.109 & $1.49, p=0.222$ \\
\hline Self-esteem slope with BMI intercept & 0.05 & 0.348 & 0.06 & 0.312 & $0.01, p=0.929$ \\
\hline Self-esteem slope with BMI slope & -0.26 & $<0.001$ & 0.00 & 0.957 & $11.46, p<0.001$ \\
\hline
\end{tabular}

Model fit, $\chi^{2}=124.1(d f=39), p<0.001, \mathrm{CFI}=0.98, \mathrm{TLI}=0.98, \mathrm{RMSEA}=0.045$. The quadratic growth factor of BMI with zero variance was included in the model 
Table 4 Correlations between the panel to panel changes of self-esteem and BMI, results from a multigroup (females, males) model

\begin{tabular}{|c|c|c|c|c|c|}
\hline \multirow[t]{2}{*}{ Correlation } & \multicolumn{2}{|c|}{ Females $(N=948)$} & \multicolumn{2}{|c|}{ Males $(N=830)$} & \multirow{2}{*}{$\begin{array}{l}\text { Gender difference } \\
\Delta \chi^{2}, p(d f=1)\end{array}$} \\
\hline & Estimate & $p$ & Estimate & $p$ & \\
\hline \multicolumn{6}{|l|}{ From 16 to 22 years } \\
\hline $\begin{array}{l}\text { Self-esteem change } \\
\text { with BMI change }\end{array}$ & 0.03 & 0.489 & 0.03 & 0.416 & $0.01, p=0.906$ \\
\hline \multicolumn{6}{|l|}{ From 22 to 32 years } \\
\hline $\begin{array}{l}\text { Self-esteem change } \\
\text { with BMI change }\end{array}$ & -0.16 & $<0.001$ & 0.11 & 0.008 & $23.94, p<0.001$ \\
\hline \multicolumn{6}{|l|}{ From 32 to 42 years } \\
\hline $\begin{array}{l}\text { Self-esteem change } \\
\text { with BMI change }\end{array}$ & -0.09 & 0.029 & 0.01 & 0.788 & $3.43, p=0.064$ \\
\hline
\end{tabular}

overweight, even if they are, and rate themselves more attractive compared to overweight women [34]. In addition, the culturally acceptable body shape types are more versatile for males as compared to the one strict slim type available for females [4]. Thus, it seems that the weight gain that took place among males between the ages of 22 and 32 has been welcomed by some of them, perhaps more likely if the gain was due to increased muscle mass, while for some others, the weight gain might have appeared as something not to be too worried about, at least not as something that jeopardizes one's self-concept at this stage of life.

Among males, the cross-sectional correlations between self-esteem and BMI were slightly positive but nonsignificant between ages 16 and 32. These non-significant associations show that body weight as captured using BMI is not very relevant for the male self-esteem but also indicate that BMI might be a somewhat problematic measure of body shape and size in males due to its inability to differentiate between tissue types, i.e., muscle vs. fat [35]. The association between BMI and self-esteem changed by the last panel at 42 years when the correlation for the first time was negative and significant. Although the effects were small, the change from the positive association of weight gain and increasing self-esteem between ages 22 and 32 to the negative crosssectional correlation between BMI and self-esteem at age 42 is nevertheless apparent. This age-moderated pattern of findings resembles well the results by Rozin and Fallon [36] and Lynch and Zellner [33] where college-age males indicated a clear desire for more muscles [33], whereas fathers of collegeage males indicated as having more extra weight due to fat than they considered ideal [36]. Similarly, a recent Finnish
Fig. 2 Development of the cross-sectional correlations between self-esteem and BMI. Estimates are from a saturated multigroup (females, males) model, with all correlations between observed variables specified. Gender differences were significant at age 22 $\left(\Delta \chi^{2}=9.7, d f=1, p=0.002\right)$, age $32\left(\Delta \chi^{2}=14.8, d f=1, p<0.001\right)$, and age $42\left(\Delta \chi^{2}=4.9, d f=1\right.$, $p=0.027) * p<0.05 * * * p<0.001$

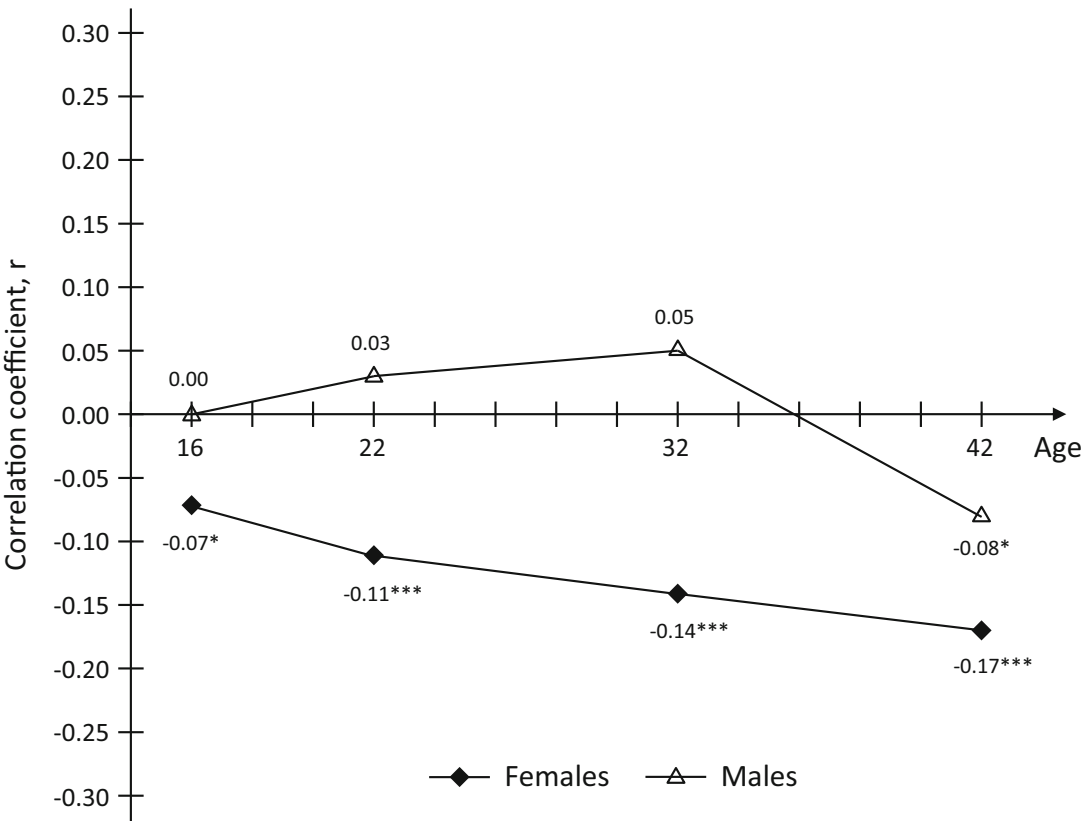


population-based study showed that males of three age groups (18-26, 27-35, and 36-49 years) were more likely to agree with the claim "I am too fat" as a function of age, while being also indicative of a trend that agreement with the claim "I am too thin" was most common in the youngest age group [29]. Thus, our results, in connection with these findings suggest that by mid-adulthood, the young adult males' desire for more muscles is replaced by considerations of having too much weight due to fat. This change has to be taken into account when relating BMI, as a measure of body size and shape, with psychological outcomes among males of different ages.

\section{Strengths and Limitations}

One of the strengths of this study is the practically complete sample of the targeted cohort in the beginning of the study. Higher attrition rates were observed in the later panels, yet only some $13 \%$ of the cases provided no follow-up data after the baseline, and in effect, an average of three (out of four) instances of measurements were available per case. Attrition was related to gender but not to self-esteem or BMI at age 16 . Nevertheless, all analyses were done using FIML estimation, which retains all cases and uses all available information in the analyzed data set in the parameter estimation, producing less biased estimates than more conventional methods of dealing with missing data [21].

The follow-up time of 26 years is exceptionally long, and studies on this subject with a follow-up period of comparable length are hard to find. Given the rarity of previous studies extending beyond the adolescent years, our study ranging from adolescence to young adulthood and further up to midadulthood can be regarded a valuable extension to the current literature. To have only four measurement points covering a period this long, however, is less than optimal, and having more measurement points would have provided a more detailed picture of the relationships between change trajectories of self-esteem and BMI.

The possibility that the observed associations between selfesteem and BMI are a product of some third variable requires a consideration. We ran analyses additionally with adjusting for basic education but that did not have any considerable effect on the results. However, there are many other candidate third variables that were not controlled for in the analyses, including e.g., chronic diseases and mental disorders. This is a limitation in our study and needs to be kept in mind when interpreting the results.

Finally, our measure of BMI was based on selfreported height and weight, which may have resulted in some underestimation in BMI levels. Comparing the mean BMI levels in our study at ages 32 and 42 to a recent Finnish report using large population-based surveys and standardized protocols for measuring height and weight suggests that this underestimation has been small [37].
Nevertheless, since BMI was used as a continuous measure in the analyses, the bias due to its underestimation has likely been only modest or negligible [38].

\section{Conclusions}

To conclude, our results show that among females higher and increasing BMI is associated with lower and more slowly increasing self-esteem from adolescence to midadulthood. The association between the two is not restricted to adolescent years but persists and even gets stronger in adulthood. Among males, self-esteem and BMI were mainly unrelated to each other, although there were some interesting age-related changes in this association. The weaker relationship between self-esteem and BMI among males may be related to normative pressures being less strict towards the male body as well as to greater problems in using BMI to measure excess body weight and size in males. The present findings highlight that public health policy and interventions that tackle weight-related stigma and discrimination are needed in order to improve well-being especially among women with higher body weight and size.

Acknowledgments The study was supported by the Emil Aaltonen Foundation, the Signe and Ane Gyllenberg's Foundation, and the Finnish Doctoral Program for Social Sciences.

Compliance with Ethical Standards The study protocol has been approved by the Ethics Committee of the National Institute for Health and Welfare, Finland. Participants were informed of the purposes of the study and that participation was voluntary, and they indicated their consent by answering the survey questionnaire.

Conflict of Interest The authors declare that they have no competing interests.

\section{References}

1. Mann M, Hosman CM, Schaalma HP, de Vries NK. Self-esteem in a broad-spectrum approach for mental health promotion. Health Educ Res. 2004;19(4):357-72.

2. Orth U, Robins RW, Widaman KF. Life-span development of selfesteem and its effects on important life outcomes. J Pers Soc Psychol. 2012;102(6):1271-88.

3. Trzesniewski KH, Donnellan MB, Moffitt TE, Robins RW, Poulton $\mathrm{R}$, Caspi A. Low self-esteem during adolescence predicts poor health, criminal behavior, and limited economic prospects during adulthood. Dev Psychol. 2006;42(2):381-90.

4. Buote VM, Wilson AE, Strahan EJ, Gazzola SB, Papps F. Setting the bar: divergent sociocultural norms for women's and men's ideal appearance in real-world contexts. Body Image. 2011;8(4):322-34.

5. Spitzer BL, Henderson KA, Zivian MT. Gender differences in population versus media body sizes: a comparison over four decades. Sex Roles. 1999;40(7-8):545-65. 
6. Stubbs J, Whybrow S, Teixeira P, Blundell J, Lawton C, Westenhoefer J, et al. Problems in identifying predictors and correlates of weight loss and maintenance: implications for weight control therapies based on behaviour change. Obes Res. 2011;12(9):688-708.

7. Miller CT, Downey KT. A meta-analysis of heavyweight and selfesteem. Pers Soc Psychol Rev. 1999;3(1):68-84.

8. Sikorski C, Luppa M, Luck T, Riedel-Heller SG. Weight stigma "Gets Under the Skin"-evidence for an adapted psychological mediation framework — a systematic review. Obesity. 2015;23(2):26676.

9. Finucane MM, Stevens GA, Cowan MJ, Danaei G, Lin JK, Paciorek CJ, et al. National, regional, and global trends in bodymass index since 1980: systematic analysis of health examination surveys and epidemiological studies with 960 country-years and 9. 1 million participants. Lancet. 2011;377(9765):557-67.

10. Puhl RM, Heuer CA. The stigma of obesity: a review and update. Obesity. 2009;17(5):941-64.

11. Wallace HM, Tice DM. Reflected appraisal through a 21st-century looking glass. In: Leary MR, Tangney JP, editors. Handbook of self and identity. 2nd ed. New York, NY, USA: The Guilford Press; 2012. p. 124-40.

12. Crandall CS, Schiffhauer KL. Anti-fat prejudice: beliefs, values, and American culture. Obes Res. 1998;6(6):458-60.

13. Ternouth A, Collier D, Maughan B. Childhood emotional problems and self-perceptions predict weight gain in a longitudinal regression model. BMC Med. 2009. doi:10.1186/1741-7015-7-46.

14. Ricciardelli LA, McCabe MP. Children's body image concerns and eating disturbance: a review of the literature. Clin Psychol Rev. 2001;21(3):325-44.

15. McCabe MP, Ricciardelli LA. Body image dissatisfaction among males across the lifespan: a review of past literature. J Psychosom Res. 2004;56(6):675-85.

16. Aro H. Parental discord, divorce and adolescent development. Eur Arch Psychiatry Neurol Sci. 1988;237(2):106-11.

17. Rosenberg M. Society and the adolescent self-image. Princeton, NJ, USA: Princeton University Press; 1965.

18. Muthén Linda K, Muthén BO. Mplus user's guide. Muthén and Muthén: Los Angeles, CA, USA; 2007.

19. Bollen KA, Curran PJ. Latent curve models: a structural equation perspective. Hoboken, NJ, USA: John Wiley \& Sons; 2006.

20. Kiviruusu O, Huurre T, Aro H, Marttunen M, Haukkala A. Self-esteem growth trajectory from adolescence to midadulthood and its predictors in adolescence. Adv Life Course Res. 2015;23:29-43.

21. Widaman III KF. Missing data: what to do with or without them. Monogr Soc Res Child Dev. 2006;71(3):42-64.

22. Allison PD. Missing data techniques for structural equation modeling. J Abnorm Psychol. 2003;112(4):545-57.

23. Hu L, Bentler PM. Cutoff criteria for fit indexes in covariance structure analysis: conventional criteria versus new alternatives. Struct Equ Model. 1999;6(1):1-55.
24. Mustillo SA, Hendrix KL, Schafer MH. Trajectories of body mass and self-concept in black and white girls: the lingering effects of stigma. J Health Soc Behav. 2012;53(1):2-16.

25. Mellor D, Fuller-Tyszkiewicz M, McCabe MP, Ricciardelli LA. Body image and self-esteem across age and gender: a short-term longitudinal study. Sex Roles. 2010;63(9-10):672-81.

26. Webster J, Tiggemann M. The relationship between women's body satisfaction and self-image across the life span: the role of cognitive control. J Genet Psychol. 2003;164(2):241-52.

27. Tiggemann M, Stevens C. Weight concern across the life-span: relationship to self-esteem and feminist identity. Int J Eat Disord. 1999;26(1):103-6.

28. Runfola CD, Von Holle A, Trace SE, Brownley KA, Hofmeier SM, Gagne DA, et al. Body dissatisfaction in women across the lifespan: results of the UNC-SELF and Gender and Body Image (GABI) studies. Eur Eat Disord Rev. 2013;21(1):52-9.

29. Algars M, Santtila P, Varjonen M, Witting K, Johansson A, Jern P, et al. The adult body: how age, gender, and body mass index are related to body image. J Aging Health. 2009;21(8):1112-32.

30. Swinburn BA, Sacks G, Hall KD, McPherson K, Finegood DT, Moodie ML, et al. The global obesity pandemic: shaped by global drivers and local environments. Lancet. 2011;378(9793):804-14.

31. Brownell KD, Kersh R, Ludwig DS, Post RC, Puhl RM, Schwartz $\mathrm{MB}$, et al. Personal responsibility and obesity: a constructive approach to a controversial issue. Health Aff. 2010;29(3):379-87.

32. Abell SC, Richards MH. The relationship between body shape satisfaction and self-esteem: an investigation of gender and class differences. J Youth Adolesc. 1996;25(5):691-703.

33. Lynch SM, Zellner DA. Figure preferences in two generations of men: the use of figure drawings illustrating differences in muscle mass. Sex Roles. 1999;40(9-10):833-43.

34. McCreary DR, Sadava SW. Gender differences in relationships among perceived attractiveness, life satisfaction, and health in adults as a function of body mass index and perceived weight. Psychol Men Masculinity. 2001;2(2):108-16.

35. Jackson AS, Stanforth PR, Gagnon J, Rankinen T, Leon AS, Rao DC, et al. The effect of sex, age and race on estimating percentage body fat from body mass index: The Heritage Family Study. Int J Obes Relat Metab Disord. 2002;26(6):789-96.

36. Rozin P, Fallon A. Body image, attitudes to weight, and misperceptions of figure preferences of the opposite sex: a comparison of men and women in two generations. J Abnorm Psychol. 1988;97(3): $342-5$.

37. Lahti-Koski M, Harald K, Saarni SE, Peltonen M, Mannisto S. Changes in body mass index and measures of abdominal obesity in Finnish adults between 1992 and 2007, the National FINRISK Study. Clin Obes. 2012;2(1-2):57-63.

38. McAdams MA, Van Dam RM, Hu FB. Comparison of self-reported and measured BMI as correlates of disease markers in US adults. Obesity. 2007;15(1):188-96.

39. Cole TJ, Bellizzi MC, Flegal KM, Dietz WH. Establishing a standard definition for child overweight and obesity worldwide: international survey. BMJ. 2000;320(7244):1240-3. 